\title{
How do Fines and Their Enforcement on Counterfeit Products Affect Social Welfare?
}

\author{
Marta Biancardi ${ }^{1} \cdot$ Andrea Di Liddo $^{2}$ (D) $\cdot$ Giovanni Villani $^{3}$ (D)
}

Accepted: 5 September 2021 / Published online: 17 September 2021

(C) The Author(s) 2021

\begin{abstract}
We consider a differential game which models the competition between a genuine and a counterfeit producer. The genuine manufacturer acts as a leader, first announcing the price of the product and the investments in advertising. After observing the leader's decisions, the counterfeiter sets the selling price of the fakes. We assume that the demand of the good is driven by the brand-name goodwill. We calculate the Stackelberg feedback equilibria and the social welfare, defined by the unweighted sum of the genuine and fakes consumers, the profit of the genuine firm, minus the enforcement costs borne by the social planner. The purpose of this paper is twofold. Firstly we study the dependence of social welfare on the amount of the fines established in the IPR law and monitoring efforts. Then, we compare prices, profits and social welfare under Nash and Stackelberg framework.
\end{abstract}

Keywords Counterfeiting $\cdot$ Social welfare $\cdot$ Differential Games

Andrea Di Liddo

andrea.diliddo@unifg.it

Marta Biancardi

marta.biancardi@uniba.it

Giovanni Villani

giovanni.villani@uniba.it

1 Dipartimento Jonico "Sistemi Giuridici ed Economici del Mediterraneo: società, ambiente, culture", University of Bari, Via Duomo, 259, 74123 Taranto, Italy

2 Department of Economics, University of Foggia, Largo Papa Giovanni Paolo II, 1, 71121 Foggia, Italy

3 Department of Economics and Finance, University of Bari, Largo Abbazia S. Scolastica, 53, 70124 Bari, Italy 


\section{Introduction}

Counterfeiting is an illicit activity infringing IPR (intellectual property rights). According to Di Liddo, (2017), "counterfeit trademark goods are goods which cannot be distinguished in their essential aspects from genuine trademark goods and which thereby infringe the rights of the owner of the trademark." In recent years, the globalization, combined with the rapid technological developments, has made counterfeiting a phenomenon of huge dimensions. Of course, counterfeiting produces a lot of damage in terms of product safety, brand value, job losses, lost revenues from legal companies, and so on.

A number of significant reports and books on the economic consequences of counterfeiting and piracy have been published by international organizations and scholars. Among them we mention (OECD/EUIPO, 2019, 2016; OECD, 2008; Chaudhry, 2017). According to Intenational Chamber of Commerce (ICC) ${ }^{1}$ "Counterfeit and pirated products put the health and safety of consumers worldwide at risk while robbing governments, businesses and communities of tax revenues, profits and legitimate jobs. The negative impacts of counterfeiting and piracy are projected to drain US\$ 4.2 trillion from the global economy and put 5.4 million legitimate jobs at risk by 2022."

The impact of the production and trade of counterfeit products is very different in the various national contexts. The extent of counterfeiting is higher in developing economies also because of the relatively weak enforcement of IP. An interesting indicator published by the OECD (General trade-related index of counterfeiting and piracy of economies, GTRICP-e $)^{2}$ gives, for example, the following values for the main world economies: China 1.44, India 0.64, Italy 0.38, Russian Federation 0.26, United States 0.14, United Kingdom 0.13, France 0.09, Germany 0.04.

In this context, the role of public authorities is to combat and to deter counterfeiters through some measures such as imposing fines in order to compensate legal firms and to protect consumers. Mathematical models for counterfeiting have been studied in a number of papers starting from Grossman and Shapiro, (1988a), (1988b). They claim that there are two types of markets for counterfeit products. In the first (the primary market), imperfectly informed consumers unwittingly purchase fakes, thinking that they are genuine. In fact, they have been deceived. Examples of these markets are consumer electronic products and medical devices. The secondary market involves consumers who are willing to purchase counterfeit products regardless of the fact that such products are not genuine (non-deceptive counterfeiting). Luxury branded products belong to this category. In the context of nondeceptive counterfeiting, which is covered in this study, we quote (Banerjee, 2003; Jørgensen \& Di Liddo, 2007; Zhang et al., 2012; Tsai et al., 2012; El Harbi et al., 2014; Buratto et al., 2016 and Crettez et al., (2020).

\footnotetext{
${ }^{1}$ https://iccwbo.org/global-issues-trends/bascap-counterfeiting-piracy [Last access 28 January 2021]

${ }^{2}$ From https://www.oecd.org/sti/ind/44088872.pdf [Last accessed 7 May 2021]: "The General TradeRelated Index of Counterfeiting for economies ( GTRICP-e) presents the relative intensity with which a given economy exports counterfeit and pirated products. The term "relative" means that for a given economy GTRIC-e indicates the average intensity of its counterfeit exports, taking the economy with the highest share of exports of counterfeit and pirated products as a benchmark."
} 
Different tools can be used to combat counterfeiting. National IPR laws are very different and quite complex. Many countries have signed international agreements which are then incorporated into national laws. The most important is the Agreement on Trade-Related Aspects of IPR (TRIPS agreement) ${ }^{3}$. A simple survey of the legal instruments available to genuine producers in some countries (including USA, Italy, Germany, France; China and Japan) is contained in IP Working Group (2018). The IPR laws of most countries provide for confiscation of counterfeit goods (especially as they enter customs). In addition to confiscation, authorities can fine anyone producing, trading or selling counterfeit goods. There are two relevant elements in a fine-scheme: the amount and the recipient of the fines. As regards the amount of fines, it is often pegged to the price of a genuine item charged by the IPR holder ${ }^{4}$. Fines are often claimed by the producers of genuine products ${ }^{5}$. Art. 45(1) of the TRIPS agreement says: "The judicial authorities shall have the authority to order the infringer to pay the right holder damages adequate to compensate for the injury the right holder has suffered because of an infringement of that person's intellectual property right by an infringer who knowingly, or with reasonable grounds to know, engaged in infringing activity." In this paper we propose a model of counterfeiting that incorporates, in a necessarily simplified way, two elements common to most IPR legislation: the proportionality of the sanction to the value of the confiscated goods if they were original; the right of the trademark owner to collect the penalty imposed on the infringer. A number of papers investigate the effect of penalties imposed on counterfeiters, on marketing strategies of original producers and their payoffs. The present paper follows this stream of investigation within the framework of non-deceptive counterfeiting. Two pioneering papers in this field are Yao, (2005a, 2005b). In Yao, (2005a), a vertically differentiated model is studied, whereby counterfeiters are assumed to produce and sell a copy of the genuine item with lower quality. Whenever a counterfeiter is caught, she must pay a unit fine proportional to the price of the genuine item. Fines are collected by the government.

In Yao, (2005b) penalties are still pegged to the retail price of the genuine items but are cashed by the IPR holder rather than by the government. This assumption has one interesting and counterintuitive consequence: the monopolist may obtain greater profits in the presence of counterfeiting than in its absence. In Di Liddo, (2018) penalties are still collected by the IPR holder but without requiring sanctions pegged to the price of genuine items. A common assumption to the above cited papers is that a competitive fringe of counterfeiters enters the market freely to supply counterfeit products up to the point where the expected price equals the expected marginal cost. Hence any strategic interaction between the genuine

\footnotetext{
${ }^{3}$ The TRIPS Agreement is Annex 1C of the Marrakesh Agreement Establishing the World Trade Organization, signed in Marrakesh, Morocco on 15 April 1994. It establishes minimum standards for the regulation by national governments of different forms of intellectual property as applied to nationals of other World Trade Organization member nations.

4 E. g., in the U.S., the Anti-counterfeiting Consumer Protection Act of 1996, S. 1136, provides civil fines pegged to the value of genuine goods.

5 For example, in June 2008, a French court ordered e-Bay pay \$63 million in damages to the luxury group LVMH, after finding that the site had facilitated the sale of counterfeits of its high fashion products.
} 
producer and counterfeiter is neglected. Differently, in Di Liddo, (2019) two firms, the genuine and the fake producers, strategically determine the price of their respective items to maximize their respective profits.

In the present paper we consider a market where a legal producer launches, at the initial time, a new product protected by conventional IPR laws and a counterfeiter illegally copies and sells the product without the permission of the genuine firm. Following (Biancardi et al., 2020), we assume that the demand of the good is driven by the brand-name reputation (goodwill) but, differently, here we suppose that the genuine manufacturer acts as a leader, first announcing the price of the product and the investments in advertising. Having observed the decisions made by the leader, the counterfeiter (follower) sets the selling price of the counterfeit asset. After calculating the Stackelberg feedback equilibrium, we consider the social welfare, defined by the unweighted sum of the genuine and fakes consumers, the profit of the genuine firm, minus the enforcement costs borne by the social planner.

The purpose of this paper is twofold. Firstly we study the dependence of social welfare on the amount of the fines established in the IPR law and monitoring efforts. Then, we compare prices, profits and social welfare under Nash and Stackelberg framework.

The rest of the present paper is organized as follows. Section 2 is devoted to the presentation of the model and the related assumptions and then, the interior Stackelberg feedback equilibrium is computed. In Sect. 3 the social welfare is obtained and in Sect. 4 numerical simulations with economic intuitions and policy implications are discussed. Finally, Sect. 5 concludes. All the proofs are placed in the Appendix.

\section{Competition Between the Genuine Producer and the Infringer}

A branded product is sold in a market by the company that owns the brand (legal firm). Let $p_{g}(t) \geq 0$ be the unit price at which the product is sold at instant $t$. Another firm (counterfeiter) introduces, at the time $t=0$, a counterfeit version of the genuine product into the same market and sells it at the unit price $p_{c}(t) \geq 0$. The counterfeit product is sold illegally and the public authority makes an effort to identify the counterfeit products that are thus seized; moreover a fine proportional to the price of the corresponding genuine good is imposed on the counterfeiter for each unit of confiscated goods. The amount of the penalty is set by legislation. We assume that consumers of fakes are aware that they are illegally purchasing counterfeit products.

A problem that arises dealing with a noncooperative game is which type of equilibrium is the most appropriate to study, for example, Nash equilibrium rather than Stackelberg equilibrium. Sometimes the answer is clearly provided by the information structure of the problem being studied. Many times, however, various types of equilibrium appear equally feasible and the following question arises: is there an equilibrium that gives each player a greater payoff than the others? Such aquestion is addressed, for example, in Pohjola, (1983), Jørgensen et al., (2001), Novak et al., (2010), Hu et al., (2011). 
In the literature about competition between original producer and counterfeiters, both Nash and Stackelberg equilibria are studied. Which equilibrium most reflects the interaction in real markets remains an open question. While in Grossman and Shapiro, (1988b), Biancardi et al., (2020), Crettez et al., (2020) Nash equilibria are investigated, here we are dealing with Stackelberg equilibria as is done in Di Liddo, (2019), Ahmadi and Yang, (2000), Choi, (2004). This means that the counterfeiter decide to enter the market and at what price to sell the counterfeit product, after having observed the genuine item price and the advertising effort of the trademark owner."

\subsection{Demand}

Demand for genuine goods depends not only on the price of the product but also on the brand reputation $G(t)$ (goodwill).

Following (Nerlove \& Arrow, 1962), we assume that the goodwill decays exponentially unless the genuine manufacturer invests in advertising. Its dynamics is described by the following linear differential equation

$$
\dot{G}(t)=h a(t)-\sigma G(t), \quad G(0)=G_{0} \geq 0,
$$

where $a(t)$ is the advertising effort of the genuine firm at time $t, h>0$ is a parameter measuring the efficiency of advertising and $\sigma \geq 0$ is the decay rate.

$G_{0}>0$ in the case of a brand already known by consumers at the time $t=0$ of the launch of the new product; otherwise it is zero.

The demand $D_{g}(t)$ for the authentic good is positively influenced by goodwill and decreases as its price increases. It also suffers from the presence of fakes as much as the difference between the prices of the two goods is large. Precisely, we assume that

$$
D_{g}(t)=G(t)\left[\alpha-\beta p_{g}(t)-\rho\left(p_{g}(t)-p_{c}(t)\right)\right]
$$

where $\alpha>0, \beta>0$ and $\rho>0$. $\rho$ measures the strength of the competition.

The demand $D_{g}(t)$ of the counterfeit product is

$$
D_{c}(t)=G(t)\left[\rho\left(p_{g}(t)-p_{c}(t)\right)\right] .
$$

Note that both the original and counterfeit products are present in the market iff

$$
0 \leq p_{c}<p_{g} ; \quad p_{g}<\frac{\alpha+\rho p_{c}}{\beta+\rho} .
$$

In the above demand functions the goodwill stock enters multiplicatively and it have been previously proposed in Buratto et al., (2016) ${ }^{6}$. A general discussion of demand functions can be found in Huang et al., (2013).

\footnotetext{
${ }^{6}$ In Buratto et al., (2016) the authors write "Note that the goodwill stock enters multiplicatively in the demand functions. This means that for any given prices, the higher the brand's reputation, as measured by the goodwill stock, the higher is the demand. Furthermore, the demands include the price differential term $\rho\left(p_{g}(t)-p_{c}(t)\right)$. Such specification, which has been adopted in, e.g. Eliashberg and Jeuland, (1986) and Martin-Herran et al., (2012), captures the idea that when making their choices, consumers look at the
} 


\subsection{Payoff}

The probability $\phi$ of detecting counterfeit products depends on the commitment of the public authority (hereinafter "government"). If the counterfeiter is not detected then his income is equal to the unit price of the fake multiplied by the quantity sold, otherwise his products are confiscated and she is obliged to pay a fine equal, for each unit of the seized good, to the product between the price of one unit of genuine product multiplied by a parameter $f>0$ set by IPR law. We set equal to zero the production cost of fakes, since it is usually considerably lower than that of the genuine product.

According to Buratto et al., (2016) and Crettez et al., (2020), we consider the competition between the two firms on a short time horizon $[0, T]$ and we do not include a discount factor in the objective functionals of the two players. The initial date corresponds to the launch of a new product by the legal manufacturer, whereas $T$ is to the end of the selling season or the end of the product's life cycle. Anyhow, model with finite time horizon are frequently used in marketing models literature (see e.g. Jørgensen and Zaccour, 2004).

The (average) counterfeiter profit is

$$
\Pi_{c}=\int_{0}^{T}\left\{(1-\phi) p_{c}(t)-\phi f p_{g}(t)\right\} D_{c}(t) d t .
$$

Following (Yao, 2005b), we assume that the fines are pocketed by the genuine firm.

The genuine producer bears both the production costs and the advertising costs necessary to keep goodwill high. Suppose production costs are linear and let $c \geq 0$ be the unit cost. Since the production cost of counterfeits is zero, the parameter $c$ also represents the degree of cost advantage of the counterfeiter vis-a-vis the genuine producer. Moreover, following most of the literature (see, e.g., the book by Jørgensen and Zaccour, (2004)), we assume that the advertising cost is convex.

The (average) genuine firm payoff is given by

$$
\Pi_{g}=\int_{0}^{T}\left\{\left(p_{g}(t)-c\right) D_{g}(t)+\phi f p_{g}(t) D_{c}(t)-\frac{\delta}{2} a^{2}(t)\right\} d t+s G(T),
$$

where $\delta>0$ and $s G(T)$ is the salvage value of goodwill at the final time $\mathrm{T}$ with $s \geq 0^{7}$.

\footnotetext{
Footnote 6 continued

price gap between the legal and illegal product. This sensitivity, or propensity to buy the illegal product, is captured by the parameter $\rho$ which reflects the amount of substitutability between the two products resulting from price differences; the larger the value of $\rho$, the higher the attraction of the fake product. Further some consumers are willing to buy the fake product only if it is cheaper than the legal product; otherwise, they prefer the legal product."

${ }^{7}$ Usually, in an optimal control problem with finite time horizon, a function measuring the value assigned to the terminal size of the state variable is included in the optimality criterion. This function is referred to as a scrap-value function or salvage function. See e.g. Seierstad and Sydsæter, (2002). In our model, according to Crettez et al., (2020), the salvage value of the brand at $T$, captures the potential future payoffs that the manufacturer can derive from all the products having the same brand name.
} 


\subsection{Stackelberg Equilibria}

In the following, the interior feedback Stackelberg equilibrium of the differential game is computed. It consists of decisions expressed as function of the current state and time. Such a solution is time consistent. The formal definition of Başar and Olsder, (1999) is included in Appendix B. The genuine firm (leader) determines the price of its product and the level of the advertising investments while the counterfeiter (the follower), having observed the decision of the leader, determines the price of the fake. We calculate backward and start solving the counterfeiter optimization problem

$$
\max _{p_{c}} \Pi_{c}
$$

Proposition 1 The optimal strategy of the counterfeiter is given by

$$
p_{c}^{*}=\frac{p_{g}(1-\phi+f \phi)}{2(1-\phi)} .
$$

See Appendix A.

Remark 1 The optimal price of the fake increases as the price of a genuine item increases. The ratio between the price of the fake and the price of the genuine product increases both with respect to the fine $f$ and the effort $\phi$.

In other words, if the fight against counterfeiting becomes stronger, both in terms of the amount of the sanctions and their enforcement, then the counterfeiter is induced to bring the price of the counterfeit goods closer and closer to that of the genuine ones in order to stay on the market by doing positive profits. Note that $p_{c}^{*}$ does not depend on the advertising effort of the genuine producer.

Proposition 2 The genuine firm (leader) determines the price of its product and the level of the advertising foreseeing the choice of the counterfeiter. Solving the Hamilton-Jacobi-Bellman (HJB) equation we obtain that if

$$
\phi<\widehat{\phi}
$$

and

$$
c<\widehat{c}
$$

then an interior equilibrium exists and it is given by

$$
\begin{aligned}
p_{g}^{*} & =\frac{2(1-\phi)(\alpha+c \beta)+c \rho(1-\phi-f \phi)}{2\{(1-\phi)(\rho+2 \beta)+\rho \phi f[\phi(1+f)-2]\}} ; \\
a^{*}(t) & =\frac{h}{\delta}\left[\frac{\Gamma}{\sigma}+\left(s-\frac{\Gamma}{\sigma}\right) e^{-\sigma(T-t)}\right]
\end{aligned}
$$

where 


$$
\begin{gathered}
\widehat{\phi}=\frac{1}{1+f}, \\
\widehat{c}=\frac{2 \alpha(1-\phi)\left[2 \rho f \phi^{2}(1+f)+(1-\phi)(\rho+2 \beta)-3 \rho f \phi\right]}{[\rho \phi(1+f)-2 \beta(1-\phi)-\rho]^{2}},
\end{gathered}
$$

and

$\Gamma=\frac{c^{2}[\rho \phi f-(1-\phi)(\rho+2 \beta)]^{2}+4 \alpha^{2}(1-\phi)^{2}-4 \alpha c(1-\phi)[(2 \beta+\rho)(1-\phi)+\rho f \phi(2 \phi(1+f)-3)]}{8(1-\phi)\{f \phi \rho[(1+f) \phi-2]+(2 \beta+\rho)(1-\phi)\}}$

Moreover, the equilibrium goodwill is

$$
G^{*}(t)=\frac{e^{-\sigma t} \psi(t)}{2 \delta \sigma^{2}}
$$

where

$$
\psi(t)=h\left[(s \sigma-\Gamma) e^{\sigma(2 t-T)}-(s \sigma-\Gamma) e^{-\sigma T}+2 \Gamma\left(e^{\sigma t}-1\right)\right]+2 \sigma^{2} G_{0} \delta .
$$

Remark 2 See Appendix A.

It is easy to show that if $c \geq \widehat{c}$ then, in equilibrium, there is no demand for the genuine good. The original manufacturer withdraws the product from the market and continues, possibly, to collect fines. However, it is rare to observe this situation in real markets and in the rest of the paper we confine ourselves to the case $c<\widehat{c}$.

Remark 3 It is easy to show that if $\phi \geq \widehat{\phi}$ then, in equilibrium, there is no demand for fakes. The original manufacturer acts as a monopolist and the equilibrium price and advertising are

$$
\begin{aligned}
p_{g}^{*} & =\frac{\alpha+c \beta}{2 \beta} ; \\
a^{*}(t) & =\frac{h}{\delta}\left[\frac{\Lambda}{\sigma}+\left(s-\frac{\Lambda}{\sigma}\right) e^{-\sigma(T-t)}\right]
\end{aligned}
$$

where

$$
\Lambda=\frac{(\alpha-\beta c)^{2}}{4 \beta}
$$

Moreover, the equilibrium goodwill is

$$
G^{*}(t)=\frac{e^{-\sigma t} \chi(t)}{2 \delta \sigma^{2}},
$$

where 


$$
\chi(t)=h\left[(s \sigma-\Lambda) e^{\sigma(2 t-T)}-(s \sigma-\Lambda) e^{-\sigma T}+2 \Lambda\left(e^{\sigma t}-1\right)\right]+2 \sigma^{2} G_{0} \delta .
$$

Remark 4 In the literature concerning competitive games between counterfeiters and sellers of original products, both the case in which players make their choices without observing the choices of the other (Nash equilibria) and the case in which the producer of genuine goods acts as a leader while the counterfeiter makes his choices being able to observe those made by the genuine producer (Stackelberg equilibria) are investigated. In Biancardi et al., (2020) the Nash equilibrium of the model presented in this paper was calculated while here we compute the Stackelberg equilibrium. Due to the large number of parameters, a general comparison between the two types of equilibrium is impossible. However, many numerical simulations, proposed in Sect. 4, give quite interesting insights.

\section{Counterfeiting and Welfare}

In this Section, we define and compute social welfare. Following almost all the literature on the subject, in the calculation of social welfare we consider the profit of the genuine producer and the surplus of consumers who buy the genuine product. Obviously, the cost incurred by the government to enforce the fines is subtracted. More controversial is the inclusion in social welfare of the surplus of consumers who buy the fakes: we include it in this paper. We analyze the possibility of considering the counterfeiter's profit or not. In particular, the counterfeit producer's profit can be added as a negative value to the computation of social welfare.

We assume that the enforcement costs borne by the social planner are quadratic with respect to enforcement $\phi$. Consequently, the social welfare $W$ is defined by

$$
W=\int_{0}^{T}\left[S_{c}(t)+S_{g}(t)+\pi_{g}(t)-\lambda \pi_{c}(t)-k \phi^{2}\right] d t,
$$

where $S_{c}$ is the surplus given by the purchase of fake product, $S_{g}$ is the one from consumers who buy the genuine product, $\pi_{g}(t)$ is the genuine instant producer profit, $\pi_{c}(t)$ is the counterfeit instant profit, $k \phi^{2}$ is the IPR enforcement cost and $\lambda=0$ or $\lambda=1$.

As usual, we compute the surplus starting from the demand function. We remember that the demand of the counterfeit product at the time $t$ and at the price $p$ is

$$
D_{c}(p)=G(t) \rho\left[p_{g}-p\right]
$$

where $p_{c} \leq p \leq p_{\text {cmax }}$ and $p_{\text {cmax }}=p_{g}$ is the maximum price such that nobody buys the product over it. Hence 


$$
S_{c}(t)=\int_{p_{c}}^{p_{g}} D_{c}(p) d p=\frac{G(t) \rho\left[p_{g}-p_{c}\right]^{2}}{2} .
$$

Let $D_{g}(p)$ denotes the legal demand function at the price $p$, i.e.

$$
D_{g}(p)=G(t)\left[\alpha-\beta p+\rho\left(p_{c}-p\right)\right],
$$

where $p_{g} \leq p \leq p_{\text {gmax }}$ and $p_{\text {gmax }}=\frac{\alpha+\rho p_{c}}{\beta+\rho}$ is the maximum price such that nobody buys the product over it. Hence, the genuine consumer's surplus is given by

$$
S_{g}(t)=\int_{p_{g}}^{p_{g \max }} D_{g}(p) d p=\frac{G(t)\left[\alpha+\rho p_{c}-(\beta+\rho) p_{g}\right]^{2}}{2(\beta+\rho)} .
$$

Having explicitly calculated the Stackelberg equilibrium of the competitive game between the two firms, it is also possible to explicitly calculate social welfare by inserting equilibrium prices and advertising into (5).

\section{Numerical Simulations}

Due to the high number of parameters present in the model and the complexity and length of the expressions that define the equilibrium itself, a general analysis of the properties of welfare is impossible. Nonetheless, a number of interesting insights can be obtained by setting specific values for most parameters and studying the problem as the remaining key parameters of the model vary. To underline our results, we assume that ${ }^{8}$

$$
\alpha=1 ; \quad \beta=1 ; \quad h=1 ; \quad \delta=1 ; \quad \sigma=1 ; \quad s=1 ; \quad T=1 ; \quad k=1 \quad G(0)=1 .
$$

\subsection{Combined Effect of Sanctions and Their Enforcement on Welfare in Stackelberg Equilibria with $\lambda=0$}

In this Subsection, the focus is to analyze the effects of some variables on the social welfare in the Stackelberg equilibrium without considering the effect of counterfeiter's profit on welfare $(\lambda=0)^{9}$. Interesting questions that we try to answer are the following: what is the range of values of $f$ and $\phi$ that give a higher social welfare than that obtained in the case in which no enforcement of the penalties is performed

\footnotetext{
${ }^{8}$ It would be interesting to use real data to estimate the parameter values used in numerical simulations. But this is outside the scope of this paper. As an analytical treatment is not possible, we have simply normalized to one all the parameters except those with respect to which we have studied the levels of welfare: $c, \rho, f, \phi$.

9 In their seminal paper, Grossman and Shapiro, (1988b) first considered trade in counterfeit products. In their model, foreign firms export counterfeits of domestic brand-name products, and the counterfeit products are of inferior quality. These assumptions were then taken up in a significant part of the literature on counterfeiting. E.g., (Choi, 2004) writes "We consider a mixed market with counterfeit producers in a two-country framework. There are two countries, the home country (America) and the foreign country (Asia). There is a single firm with the genuine brand, which is sold to the world market, but many foreign firms produce counterfeits. The monopolist does not license its technology to foreign firms."
} 


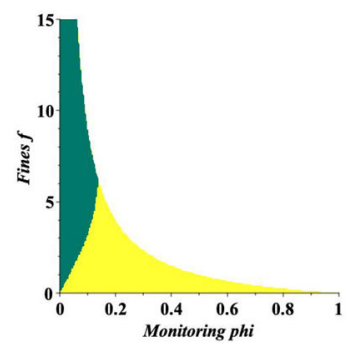

(a) $c=0.30 ; \quad \rho=0.30$

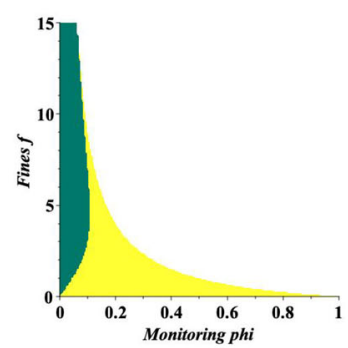

(d) $c=0.60 ; \quad \rho=0.30$

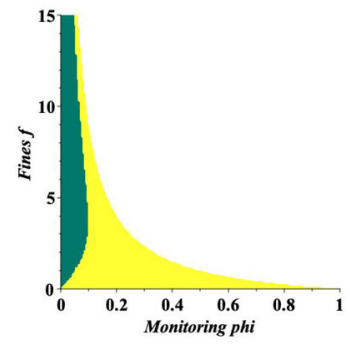

(g) $c=0.80 ; \quad \rho=0.30$

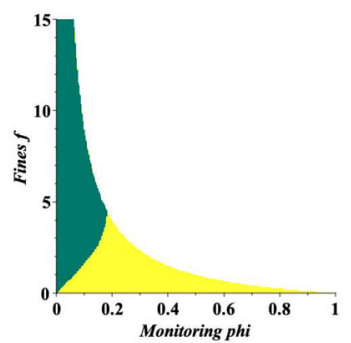

(b) $c=0.30 ; \quad \rho=0.60$

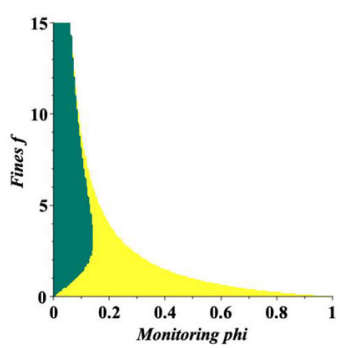

(e) $c=0.60 ; \quad \rho=0.60$

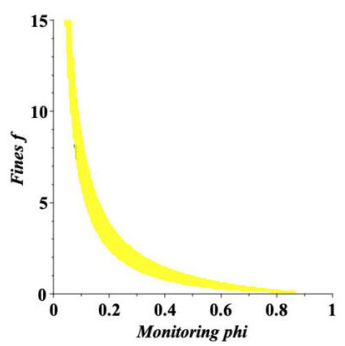

(h) $c=0.80 ; \quad \rho=0.60$

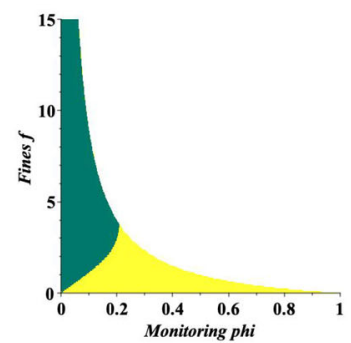

(c) $c=0.30 ; \quad \rho=0.90$

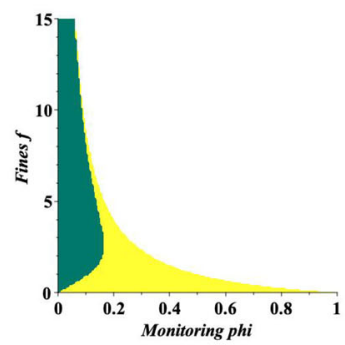

(f) $c=0.60 ; \quad \rho=0.90$

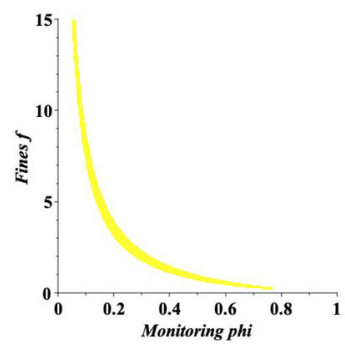

(i) $c=0.80 ; \quad \rho=0.90$

Fig. 1 The green surface denotes the combination of $(\phi, f)$ such that the social welfare $W$ with $\lambda=0$ is larger than $W_{0}$. (Color figure online)

by the social planner? In other words: for which values of the parameters $f$ and $\phi$ is the level of welfare greater than that obtained in the absence of monitoring $(\phi=0)$ ? Moreover, for which values of the parameters $f$ and $\phi$ the level of welfare is greater than that obtained in the case of the maximum monitoring value $(\phi=\widehat{\phi})$ ?

We illustrate the results of our simulations in the Figs. 1-2. In both figures, the yellow surface represents the area such that both demands of genuine and counterfeit products are positive. In this area, the price of the fake is lower than the price of the genuine product. In Fig. 1, the green surface represents the area such that the level of welfare $W$ in formula (5) subject to constraints given by inequalities (1) and (2) is larger than the one obtained assuming $\phi=0$, that we denote by $W_{0}$. In this way we are able to determine the combinations of fines $f$ and monitoring $\phi$ that improve the social welfare with respect to the scenario without government intervention. 


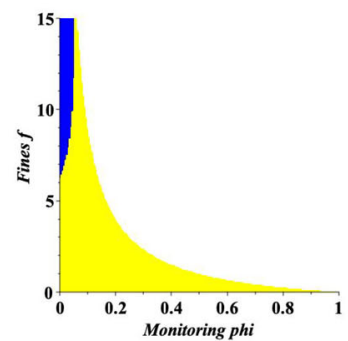

(a) $c=0.30 ; \quad \rho=0.30$

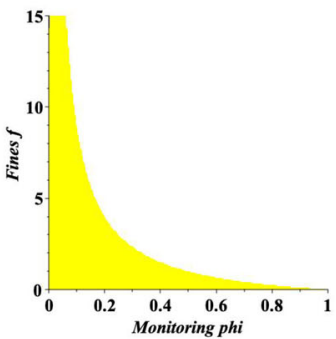

(d) $c=0.60 ; \quad \rho=0.30$

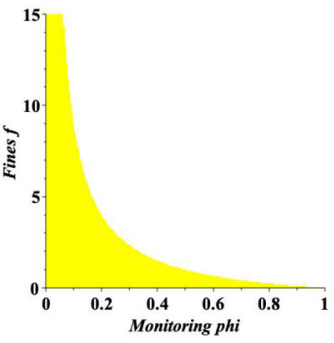

(g) $c=0.80 ; \quad \rho=0.30$

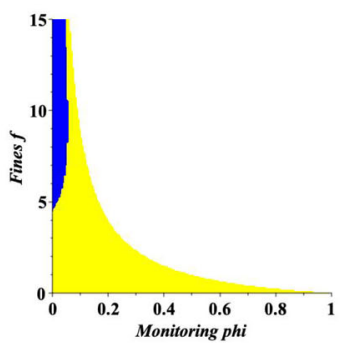

(b) $c=0.30 ; \quad \rho=0.60$

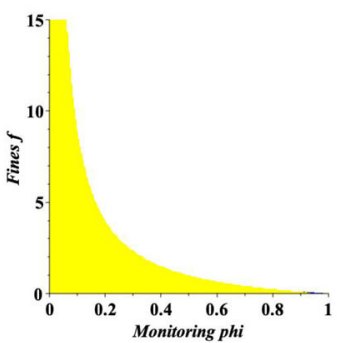

(e) $c=0.60 ; \quad \rho=0.60$

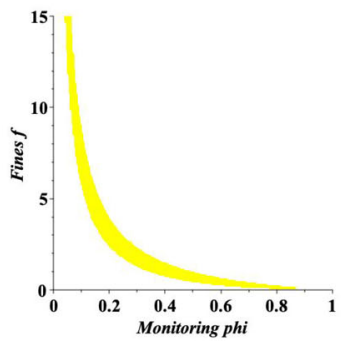

(h) $c=0.80 ; \quad \rho=0.60$

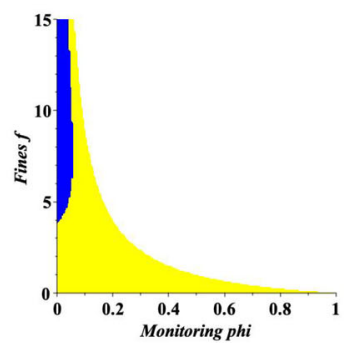

(c) $c=0.30 ; \quad \rho=0.90$

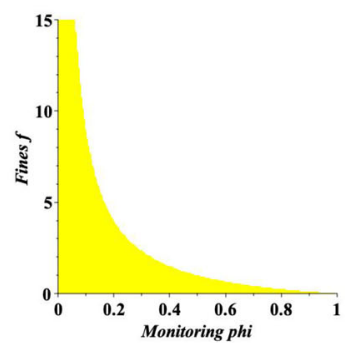

(f) $c=0.60 ; \quad \rho=0.90$

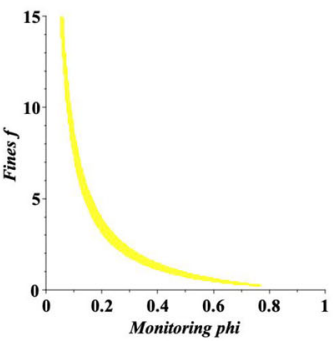

(i) $c=0.80 ; \quad \rho=0.90$

Fig. 2 The blue surface denotes the combination of $(\phi, f)$ such that the social welfare $W$ with $\lambda=0$ is smaller than $W_{\widehat{\phi}}$. (Color figure online)

Fig. 1(a-c) depict the situation with a low production cost $c=0.30$ and different levels of counterfeiting intensity, namely $\rho=0.30$ (low), $\rho=0.60$ (medium), and $\rho=0.90$ (high). Fig. 1(d)-1(f) show the situation with a medium production cost $c=0.60$ while Fig. 1(g)-1(i) illustrate the situation with a high production cost $c=0.80$.

Some interesting economic intuitions can arise. If we consider the counterfeiting of goods that require a medium-low production cost, the area of parameters $f$ and $\phi$, for which welfare improves compared to not fighting counterfeiting, widens as $\rho$ increases. This implies that the public authority, as counterfeiting increases, has a wider range of political actions (monitoring and fines) to improve welfare. Instead, if the cost of production is high, the green area exists only for low levels of counterfeiting. In this scenario, the public authority does not implement any monitoring policy to improve the level of welfare as counterfeiting increases. This 
effect seems counterintuitive and may depend on the fact that welfare also takes into account the surplus of consumers of counterfeit goods.

At the same strength of competition $\rho$, the area of parameters $f$ and $\phi$ for which welfare improves compared to not fighting counterfeiting, shrinks as $c$ increases. This effect could be explained by the fact that an increase in production costs induces the genuine producer to raise the price by reducing the surplus of consumers of the branded good.

An interesting feature shown by the figures is the following: the range of enforcement parameters that are welfare improving initially increases as $f$ increases and then decreases. In other words, there appears to be a level of sanctions that maximizes the range of enforcement being welfare improving. In Fig. 2, the blue surface represents the area such that the level of welfare obtained assuming $\phi=\widehat{\phi}$, that we denote by $W_{\widehat{\phi}}$, is larger than $W$ obtained in formula (5) subject to constraints given by inequalities (1) and (2). In this way we are able to determine the combinations of fines $f$ and monitoring $\phi$ that compare the social welfare with respect to the scenario with government intervention $\phi=\widehat{\phi}$.

As illustrated in Fig. 2(a-c), at the same low cost production $c$, the area of parameters $f$ and $\phi$, for which welfare $W_{\widehat{\phi}}$ improves compared to social welfare $W$, widens as $\rho$ goes up. It is evident that this result exists only in correspondence with high fines $f$, which contribute to increasing the profit of legal firms with respect to the maximum monitoring cost $k \widehat{\phi}$. Moreover, when counterfeiting increases, the level of the applicable fine decreases. This implies that the high cost of monitoring $k \widehat{\phi}$ can be amortized by the more widespread counterfeiting that ensure greater compensation to genuine firms. Vice versa, for medium-high costs, (see Fig. 2(d)2(i)) there are no combinations of $f$ and $\phi$ so it is advisable to adopt the maximum level of monitoring to obtain better welfare. Intuitively, this is due to higher profits of genuine firms compared with those obtained by the latter in correspondence with monitoring $\widehat{\phi}$.

\subsection{Combined Effect of Sanctions and Their Enforcement on Welfare in Stackelberg Equilibria with $\lambda=1$}

In this Subsection, we analyze the case in which the counterfeit producer's profit is considered as a negative value to the computation of social welfare. Comparing Fig. (1)-(3) $(\lambda=0$ and $\lambda=1)$, we observe that the presence of the counterfeiter's profit in welfare determines an increase in the combinations of $(\phi, f)$ for which the intervention of the state is an improvement over the situation of not acting. Moreover, comparing Fig. (2)-(4), we show how the presence of the counterfeiter's profit increases the area in which the maximum intervention to combat counterfeiting exceeds welfare in the equilibrium. In conclusion, the presence of the counterfeiter's profit with a negative impact on welfare determines an increase in the possibilities of the public authority in the fight against counterfeiting by means of sanctioning and control instruments. 


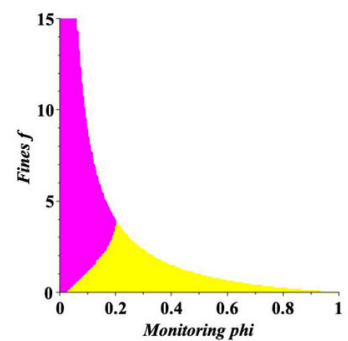

(a) $c=0.30 ; \quad \rho=0.30$

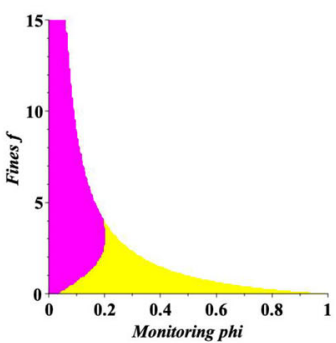

(d) $c=0.60 ; \quad \rho=0.30$

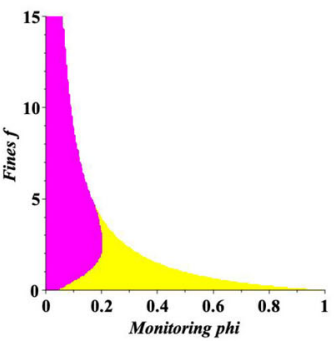

(g) $c=0.80 ; \quad \rho=0.30$

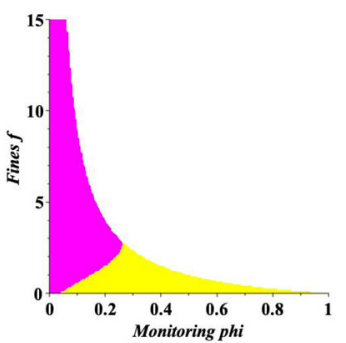

(b) $c=0.30 ; \quad \rho=0.60$

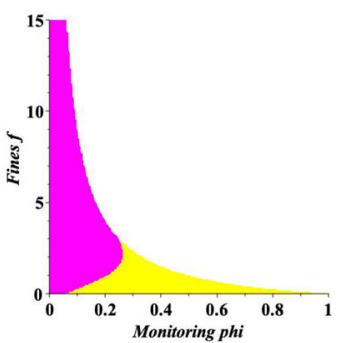

(e) $c=0.60 ; \quad \rho=0.60$

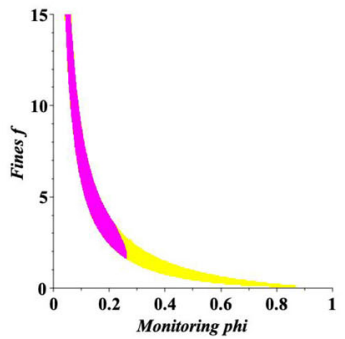

(h) $c=0.80 ; \quad \rho=0.60$

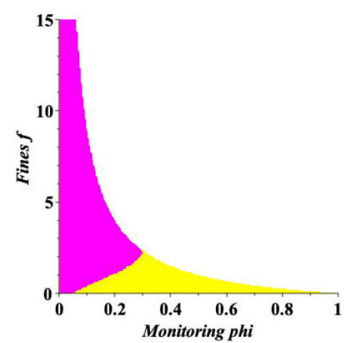

(c) $c=0.30 ; \quad \rho=0.90$

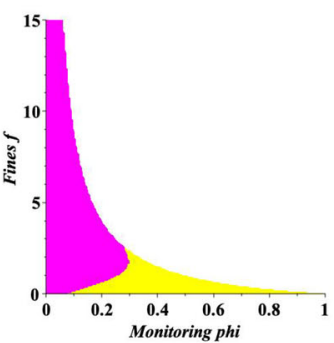

(f) $c=0.60 ; \quad \rho=0.90$

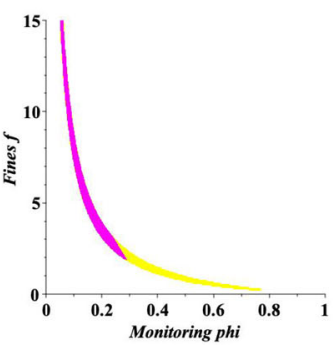

(i) $c=0.80 ; \quad \rho=0.90$

Fig. 3 The magenta surface denotes the combiation of $(\phi, f)$ such that the social welfare $W$ with $\lambda=1$ is larger than $W_{0}$. (Color figure online)

\subsection{Comparison of Prices, Profits and Welfare in Nash and Stackelberg Equilibria}

Now, we are interested to compare prices and profits of genuine and counterfeiter under Stackelberg model given in Sect. 2.2 with the Nash one, given in Biancardi et al., (2020), denoted by $\left(p_{g s}^{*}, p_{c s}^{*}, \Pi_{g s}^{*}, \Pi_{c s}^{*}\right)$ and $\left(p_{g n}^{*}, p_{c n}^{*}, \Pi_{g n}^{*}, \Pi_{c n}^{*}\right)$, respectively. To carry out this analysis, we have assumed a low and a high level of fines $f$, of production cost $c$ and of the intensity of counterfeiting $\rho$ and we have combined them. Figs. 5 and 6 depict the comparison among prices and profits when monitoring effort $\phi$ changes between $[0, \widehat{\phi}]$. In general, the profits of the two players in the Stackelberg game model are higher than that in the Nash game model. Concerning prices, we observe that when production costs $c$ are low, the prices under Stackelberg equilibrium are always higher than that under Nash model. 


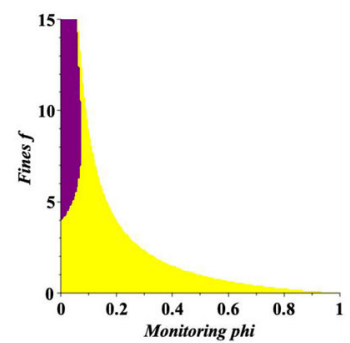

(a) $c=0.30 ; \quad \rho=0.30$

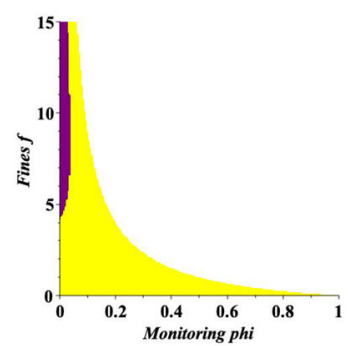

(d) $c=0.60 ; \quad \rho=0.30$

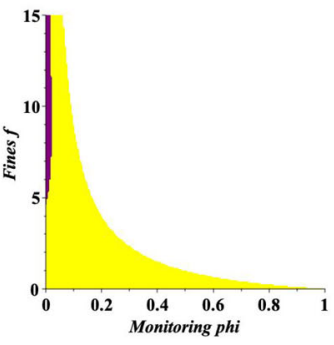

(g) $c=0.80 ; \quad \rho=0.30$

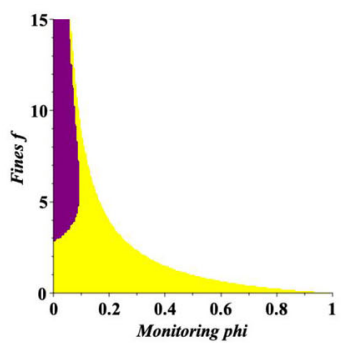

(b) $c=0.30 ; \quad \rho=0.60$

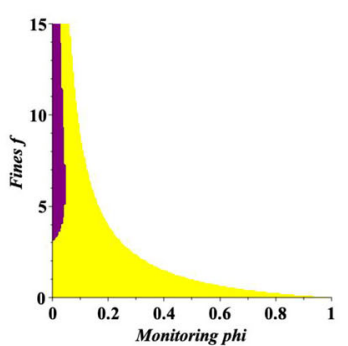

(e) $c=0.60 ; \quad \rho=0.60$

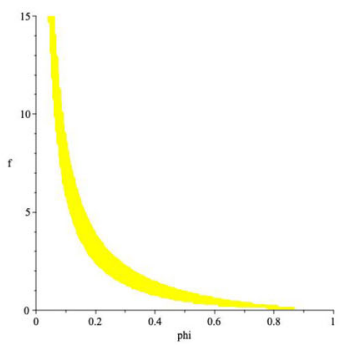

(h) $c=0.80 ; \quad \rho=0.60$

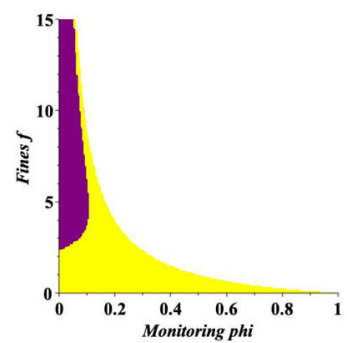

(c) $c=0.30 ; \quad \rho=0.90$

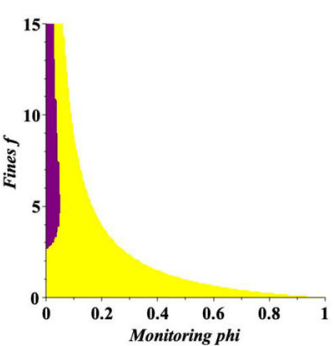

(f) $c=0.60 ; \quad \rho=0.90$

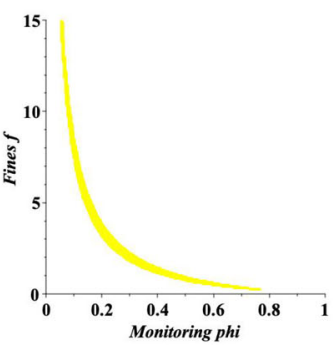

(i) $c=0.80 ; \quad \rho=0.90$

Fig. 4 The purple surfare denotes the combiation of $(\phi, f)$ such that the social welfare $W$ with $\lambda=1$ is smaller than $W_{\widehat{\phi}}$. (Color figure online)

Furthermore, this gap increases when the level of counterfeiting $\rho$ goes up both assuming low and high fines. Instead, the increase in production costs $c$ determines that Nash prices are lower than Stackelberg ones for low levels of monitoring; the opposite happens when $\phi$ raises up. It is also evident that the increase in monitoring leads to an increase in prices which is more sensitive for counterfeiters in both equilibria.

As illustrated in Fig. 6, we observe how both the genuine and counterfeiter profits under Stackelberg game can significantly improve as compared to the Nash game when the level of $\rho$ increases and for any level of fines. On the other hand, if the cost of production increases, while the genuine Stackelberg profits are always greater than those in Nash context, the Stackelberg profits of counterfeiters turn out to be larger than those in the Nash equilibrium only for low monitoring values, for any value of fines. 


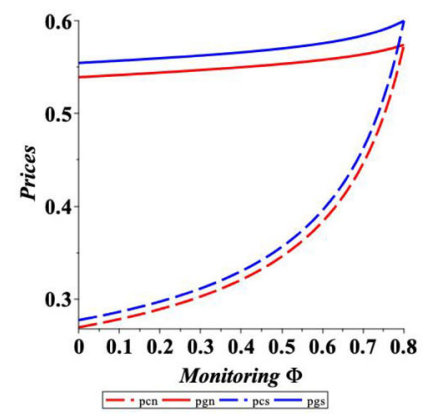

(a) $c=0.20 ; \rho=0.20 ; f=0.25$

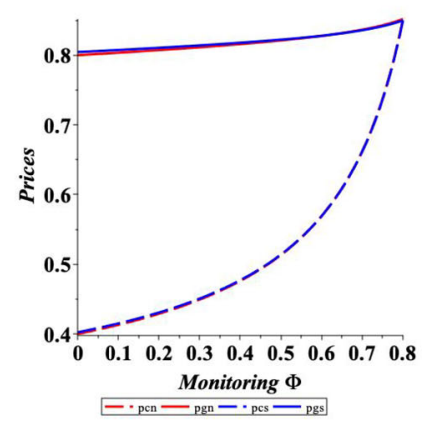

(c) $c=0.70 ; \rho=0.20 ; f=0.25$

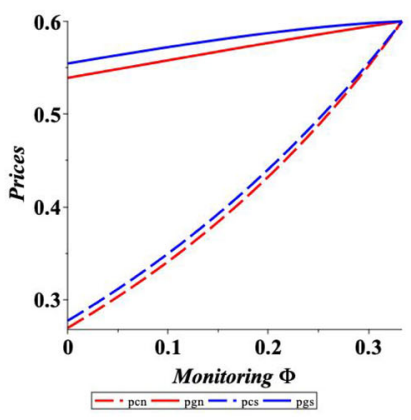

(e) $c=0.20 ; \rho=0.20 ; f=2$

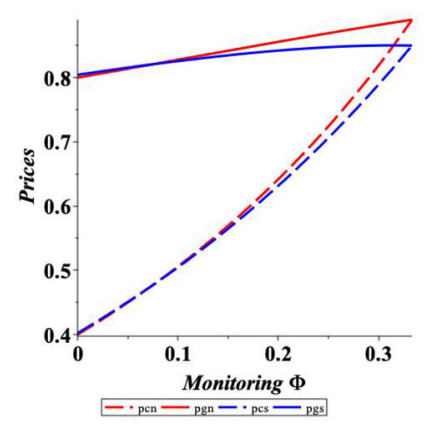

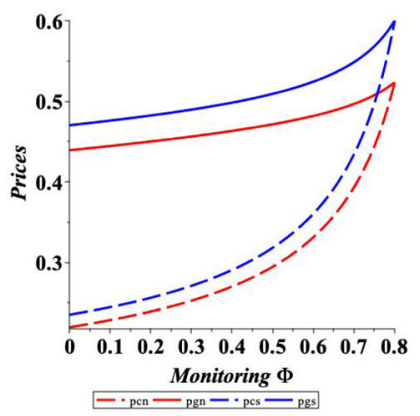

(b) $c=0.20 ; \rho=0.70 ; f=0.25$

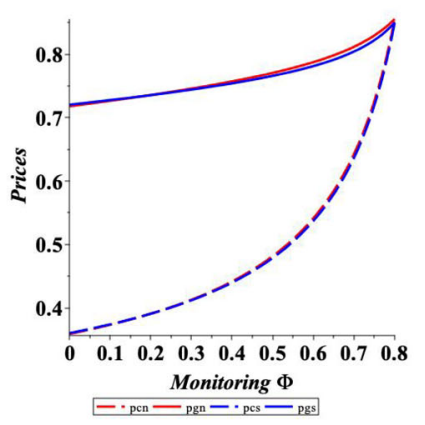

(d) $c=0.70 ; \rho=0.70 ; f=0.25$

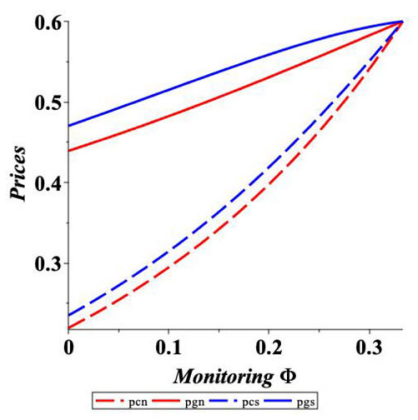

(f) $c=0.20 ; \rho=0.70 ; f=2$

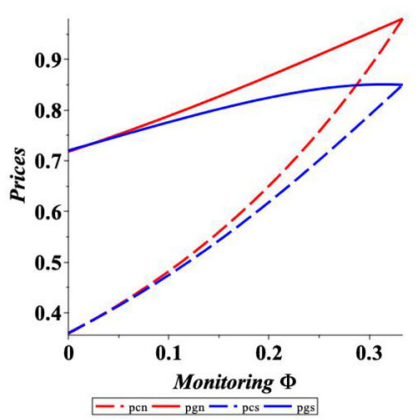


4Fig. 5 Comparison among prices in Nash (red) and Stackelberg (blue) equilibria when the monitoring effort $\phi$ changes in $[0, \widehat{\phi}]$. The solid lines denote the prices of legal firms while the dash lines the prices of counterfeiters. (Color figure online)

A natural way to explain this is that, in the case in which the counterfeiter can observe, before fixing the price of the fakes, both the price of genuine goods and the advertising investment, genuine producer benefits from it, obtaining higher profits with respect to Nash scenario, for all value of cost production, fines and monitoring. Instead, counterfeiter takes advantage both for lower production costs or, in case of high level of cost, with lower monitoring activity. This is despite the fact that prices of both products increase. The higher prices are offset by more conspicuous advertising investments and, consequently, by the higher level of goodwill.

Finally, Fig. 7 proposes the comparison between Stackelberg and Nash welfare. The yellow surface represents the area such that both demands of genuine and counterfeit products are positive in both equilibria. The red surface denotes the combination of $(\phi, f)$ such that the social welfare in the Stackelberg equilibrium is larger than welfare computed in the Nash equilibrium. By fixing the level of counterfeiting $\rho$, Stackelberg welfare increases relative to Nash one, when production costs increase. In particular, when costs are low, the set of combinations $(\phi, f)$ for which Stackelberg welfare exceeds Nash one is obtained for high fines, as illustrated in Fig. 7(a-c). However, for moderate-high costs, no regularity is apparent. Concluding, as for which model a firm should use depends on the structure of the firm. If the genuine firm plays a leading role, then the Stackelberg game is preferred. If the powers of the genuine and counterfeiter are similar, the Nash game model should be used.

\section{Conclusion}

In this paper we have considered a differential game modelling the competition between a genuine and a counterfeiter producer in a Stackelberg framework. The genuine manufacturer acts as a leader, first announcing the price of the product and the amount of investments in advertising. Having observed the decisions made by the leader, the counterfeiter (follower) decides the selling price of the counterfeit asset. The demand of the good is driven by the brand-name goodwill. We also have calculated social welfare defined, as in Yao, (2005a), by the unweighted sum of the genuine and fakes surplus consumers, the profit of the genuine firm, minus the enforcement costs borne by the social planner. Moreover, we have considered the possibility that welfare can be affected negatively by counterfeiter's profit.

We have addressed different questions. What is the range of values of fines and monitoring that give a higher social welfare than that obtained in the case in which no enforcement of the penalties is performed by the social planner? Moreover, for which values of fines and monitoring the level of welfare is greater than that obtained in the case of the maximum monitoring effort? In both cases we have observed how the variation in production costs and counterfeiting intensity 


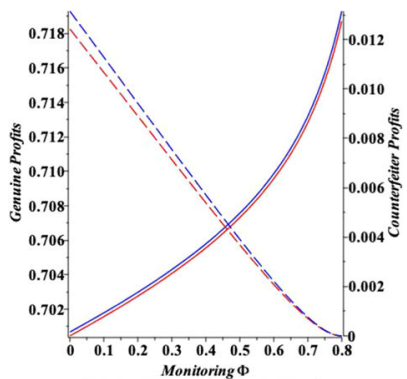

$-\Pi_{\mathrm{gn}}-\Pi_{\mathrm{gs}}--\Pi_{\mathrm{en}}--\Pi \mathrm{cs}$

(a) $c=0.20 ; \rho=0.20 ; f=0.25$;

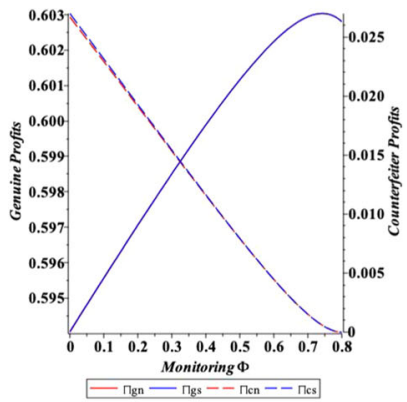

(c) $c=0.70 ; \rho=0.20 ; f=0.25$

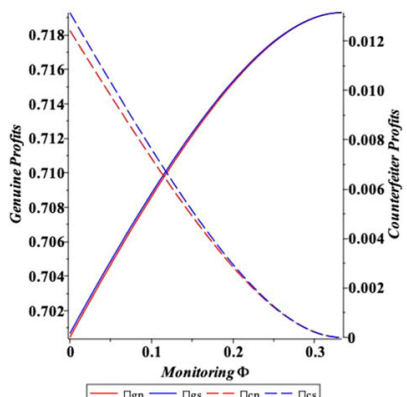

(e) $c=0.20 ; \rho=0.20 ; f=2$

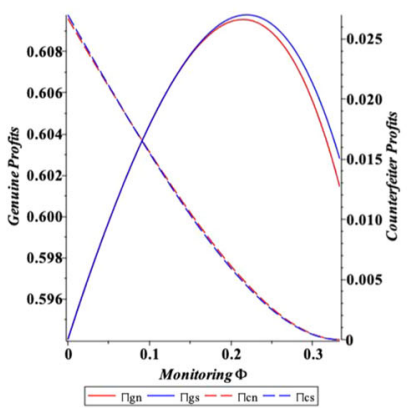

(g) $c=0.70 ; \rho=0.20 ; f=2$

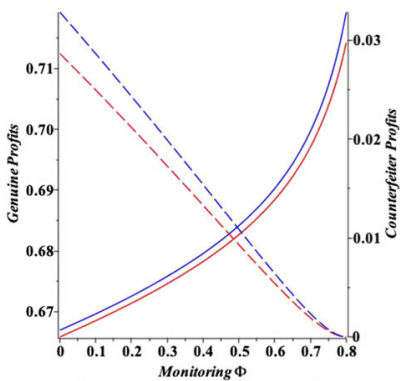

$-\pi \mathrm{gn}-\Pi_{\mathrm{gs}}--\Pi_{\mathrm{en}}--\Pi \mathrm{es}$

(b) $c=0.20 ; \rho=0.70 ; f=0.25$

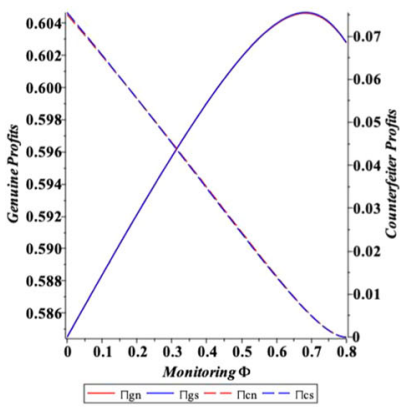

(d) $c=0.70 ; \rho=0.70 ; f=0.25$

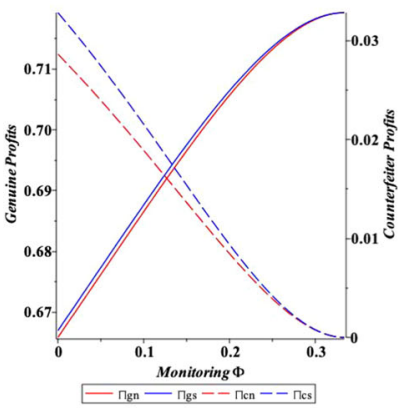

(f) $c=0.20 ; \rho=0.70 ; f=2$

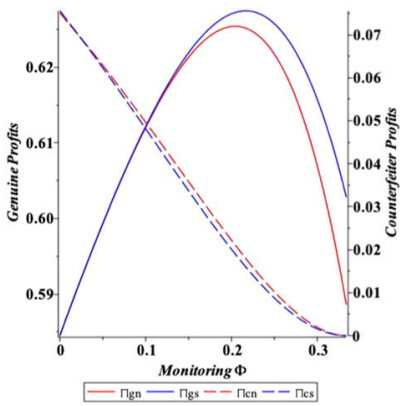

(h) $c=0.70 ; \rho=0.70 ; f=2$ 
4Fig. 6 Comparison among profits in Nash (red) and Stackelberg (blue) equilibria when the monitoring effort $\phi$ changes in $[0, \widehat{\phi}]$. The solid lines denote the profits of legal firms while the dash lines the prices of counterfeiters. (Color figure online)

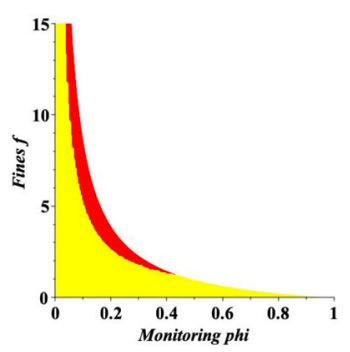

(a) $c=0.30 ; \quad \rho=0.30$

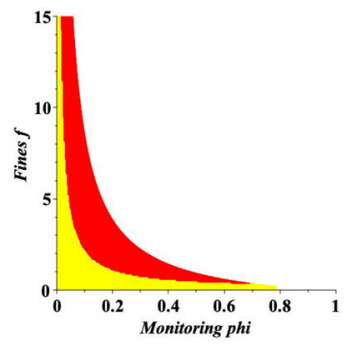

(d) $c=0.60 ; \quad \rho=0.30$

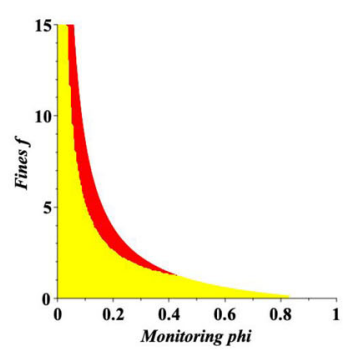

(b) $c=0.30 ; \quad \rho=0.60$

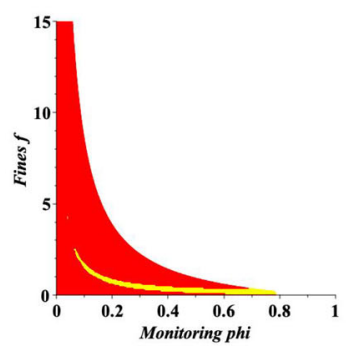

(e) $c=0.60 ; \quad \rho=0.60$

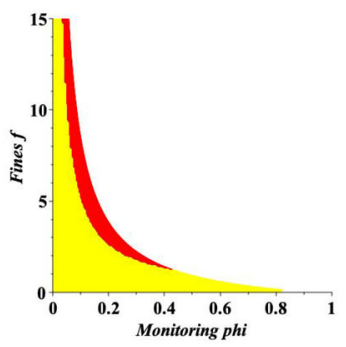

(c) $c=0.30 ; \quad \rho=0.90$

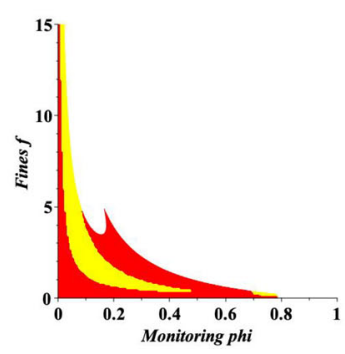

(f) $c=0.60 ; \quad \rho=0.90$

Fig. 7 The red surface denotes the combination of $(\phi, f)$ such that the social welfare in the Stackelberg equilibrium is larger than welfare computed in the Nash equilibrium. (Color figure online)

characterize these comparisons assuming the presence or absence of counterfeiter's profit.

In addition, we have compared Stackelberg equilibria with the Nash equilibria obtained in Biancardi et al., (2020). Some interesting economic observations emerged. Concerning prices, we have observed that, when production costs are low, the prices under Stackelberg equilibrium are always higher than that under Nash model. On the other hand, the increase in production costs determines that Nash prices are lower than Stackelberg ones for low levels of monitoring. We have shown that the increase in monitoring leads to an increase in prices which is more sensitive for counterfeiters in both equilibria.

In general, by numerical simulations, it turned out that the profits of the two players in the Stackelberg game model are higher than that in the Nash game model. The genuine and counterfeiter profits under Stackelberg game significantly improve as compared to the Nash game when the level of competition strength increases and for any level of fines. On the other hand, if the cost of production increases, while the genuine Stackelberg profits are always greater than those in Nash context, the Stackelberg profits of counterfeiters turn out to be larger than those in the Nash equilibrium only for low monitoring values, for any value of fines. 
Finally, we have proposed the comparison between Stackelberg and Nash welfare showing that Stackelberg welfare increases relative to Nash one, when production costs increase. In particular, when costs are low, the combination of fines and monitoring for which Stackelberg welfare exceeds Nash one is obtained for high fines. However, for moderate-high costs, no regularity is apparent.

Concluding, as for which model a firm should use depends on the structure of the firms. If the genuine firm plays a leading role, then the Stackelberg game is preferred. If the powers of the genuine and counterfeiter are similar, the Nash game model should be used.

In this paper, the amount of sanctions and its enforcement has been considered exogenous with respect to the game. It would be very interesting to consider a threeplayer game in which the social planner strategically decides the amount of penalties and the level of enforcement and, subsequently, the two companies make their own choices. Unfortunately, this problem seems analytically intractable and can possibly be considered in a subsequent paper by numerical methods for the solution of differential games.

\section{Appendix}

\section{Appendix A}

Proof of Prop. 1 The counterfeiter does not affect the evolution of goodwill. She just takes the (equilibrium) path of goodwill as given (basically she faces a static problem) and maximizes the function $\pi_{c}=\left\{(1-\phi) p_{c}(t) D_{c}(t)-\phi f p_{g}(t) D_{c}(t)\right\}$. The first order condition is:

$$
\frac{\partial \pi_{c}}{\partial p_{c}}=0
$$

and so we obtain:

$$
p_{c}^{*}=\frac{p_{g}(1-\phi+f \phi)}{2(1-\phi)}
$$

Note that $\frac{\partial^{2} \pi_{c}}{\partial p_{c}^{2}}=-2 \rho(1-\phi)<0$, which ensures that $p_{c}^{*}$ is a maximum.

Proof of Prop. 2 The HJB equation of genuine firm is: 


$$
\begin{aligned}
-\frac{\partial V_{g}}{\partial t}(t, G(t))= & \max _{p_{g}, a}\left\{\left(p_{g}(t)-c\right) D_{g}(t)+\phi f p_{g}(t) D_{c}(t)-\frac{\delta}{2} a^{2}(t)\right. \\
& \left.+\frac{\partial V_{g}}{\partial G}(t, G(t))(h a(t)-\sigma G(t))\right\}
\end{aligned}
$$

Substituting the value of $p_{c}^{*}\left(p_{g}\right)$ in the HJB of genuine firm and differentiating the right-hand-side (RHS) of (7) with respect to $p_{g}$ and $a$ lead to:

$$
\begin{aligned}
& G\left[\left(-2 p_{g}+p_{c}^{*}\left(p_{g}\right)+c+2 \phi f p_{g}-\phi f p_{c}^{*}\left(p_{g}\right)\right) \rho+\alpha-2 \beta p_{g}+c \beta\right]=0 \\
& \quad-\delta a+h \frac{\partial V_{g}}{\partial G}=0
\end{aligned}
$$

and so:

$$
\begin{gathered}
p_{g}^{*}=\frac{2(1-\phi)(\alpha+c \beta)+c \rho(1-\phi-f \phi)}{2\{(1-\phi)(\rho+2 \beta)+\rho \phi f[\phi(1+f)-2]\}} \\
a^{*}=\frac{h}{\delta} \frac{\partial V_{g}}{\partial G}
\end{gathered}
$$

Note that the Hessian matrix of RHS with respect to $p_{g}$ and $a$ is a diagonal matrix and $\frac{\partial^{2} R H S}{\partial a^{2}}=-\delta<0$;

$$
\frac{\partial^{2} R H S}{\partial p_{g}^{2}}=-\frac{G\left[\rho\left(f^{2} \phi^{2}-(2-\phi) f \phi+1-\phi\right)+2 \beta(1-\phi)\right]}{1-\phi}<0
$$

whenever $\phi<\frac{1}{1+f}$. Hence $\left(p_{g}^{*}, a^{*}\right)$ is a maximum.

Replacing $p_{g}^{*}$ in $p_{c}^{*}\left(p_{g}\right)$ leads to the following price of fake producer:

$$
p_{c}^{*}=\frac{(1-\phi+f \phi)[2(1-\phi)(\alpha+c \beta)+c \rho(1-\phi-f \phi)]}{4(1-\phi)\{(1-\phi)(\rho+2 \beta)+\rho \phi f[\phi(1+f)-2]\}}
$$

Substituting in the (7) the optimal values (8), (9), (10), we have:

$$
\begin{aligned}
-\frac{\partial V_{g}}{\partial t}= & G\left\{\frac{c^{2}[\rho \phi f-(1-\phi)(\rho+2 \beta)]^{2}+4 \alpha^{2}(1-\phi)^{2}}{8(1-\phi)\{f \phi \rho[(1+f) \phi-2]+(2 \beta+\rho)(1-\phi)\}}\right. \\
& \left.-\frac{4 \alpha c(1-\phi)[(2 \beta+\rho)(1-\phi)+\rho f \phi(2 \phi(1+f)-3)]}{8(1-\phi)\{f \phi \rho[(1+f) \phi-2]+(2 \beta+\rho)(1-\phi)\}}\right\} \\
& -\sigma G\left(\frac{\partial V_{g}}{\partial G}\right)+\left(\frac{\partial V_{g}}{\partial G}\right)^{2} \frac{h^{2}}{2 \delta}
\end{aligned}
$$

We suppose that the value function is a linear function of the state variable:

$$
V_{g}(t, G(t))=x(t) G+z(t)
$$

and so 


$$
\frac{\partial V_{g}}{\partial t}=\dot{x} G+\dot{z}
$$

and

$$
\frac{\partial V_{g}}{\partial G}=x
$$

It follows that

$$
a=\frac{h}{\delta} x(t) .
$$

Substituting in (11), we obtain:

$$
\begin{aligned}
-(\dot{x} G+\dot{z})= & G\left\{\frac{c^{2}[\rho \phi f-(1-\phi)(\rho+2 \beta)]^{2}+4 \alpha^{2}(1-\phi)^{2}}{8(1-\phi)\{f \phi \rho[(1+f) \phi-2]+(2 \beta+\rho)(1-\phi)\}}+\right. \\
& \left.-\frac{4 \alpha c(1-\phi)[(2 \beta+\rho)(1-\phi)+\rho f \phi(2 \phi(1+f)-3)]}{8(1-\phi)\{f \phi \rho[(1+f) \phi-2]+(2 \beta+\rho)(1-\phi)\}}-\sigma x\right\}+\frac{h^{2} x^{2}}{2 \delta}
\end{aligned}
$$

(12) must be verified for any value of $G$. Hence, we have:

$$
\begin{aligned}
-\dot{x}+\sigma x= & \left\{\frac{c^{2}[\rho \phi f-(1-\phi)(\rho+2 \beta)]^{2}+4 \alpha^{2}(1-\phi)^{2}}{8(1-\phi)\{f \phi \rho[(1+f) \phi-2]+(2 \beta+\rho)(1-\phi)\}}+\right. \\
& \left.-\frac{4 \alpha c(1-\phi)[(2 \beta+\rho)(1-\phi)+\rho f \phi(2 \phi(1+f)-3)]}{8(1-\phi)\{f \phi \rho[(1+f) \phi-2]+(2 \beta+\rho)(1-\phi)\}}\right\} \\
\dot{z}= & -\frac{h^{2} x^{2}}{2 \delta}
\end{aligned}
$$

The solution of this system of differential equations is given by:

$$
\begin{aligned}
& x(t)=\frac{\Gamma}{\sigma}+C_{1} e^{\sigma t} \\
& z(t)=-\frac{h^{2}}{2 \delta}\left[\frac{\Gamma^{2}}{\sigma^{2}} t+\frac{1}{2 \sigma} C_{1}^{2} e^{2 \sigma t}+\frac{2 \Gamma}{\sigma^{2}} C_{1} e^{\sigma t}\right]+C_{2}
\end{aligned}
$$

where $C_{1}$ and $C_{2}$ are integration constants and

$$
\begin{aligned}
\Gamma= & \left\{\frac{c^{2}[\rho \phi f-(1-\phi)(\rho+2 \beta)]^{2}+4 \alpha^{2}(1-\phi)^{2}}{8(1-\phi)\{f \phi \rho[(1+f) \phi-2]+(2 \beta+\rho)(1-\phi)\}}+\right. \\
& \left.-\frac{4 \alpha c(1-\phi)[(2 \beta+\rho)(1-\phi)+\rho f \phi(2 \phi(1+f)-3)]}{8(1-\phi)\{f \phi \rho[(1+f) \phi-2]+(2 \beta+\rho)(1-\phi)\}}\right\}
\end{aligned}
$$

Using the boundary condition $V_{g}(T, G(T))=s G(T)$, we obtain $x(T)=s$ and $z(T)=0$, and so: 


$$
\begin{aligned}
& C_{1}=\left(s-\frac{\Gamma}{\sigma}\right) e^{-\sigma T} \\
& C_{2}=\frac{h^{2}}{2 \delta}\left[\frac{\Gamma^{2}}{\sigma^{2}} T+\frac{1}{2 \sigma}\left(s-\frac{\Gamma}{\sigma}\right)^{2}+\frac{2 \Gamma}{\sigma^{2}}\left(s-\frac{\Gamma}{\sigma}\right)\right]
\end{aligned}
$$

and consequently:

$$
\begin{aligned}
x(t)= & \frac{\Gamma}{\sigma}+\left(s-\frac{\Gamma}{\sigma}\right) e^{-\sigma(T-t)} \\
z(t)= & \frac{h^{2}}{2 \delta}\left[\frac{\Gamma^{2}}{\sigma^{2}}(T-t)+\frac{1}{2 \sigma}\left(s-\frac{\Gamma}{\sigma}\right)^{2}\left(1-e^{-2 \sigma(T-t)}\right)\right. \\
& \left.+\frac{2 \Gamma}{\sigma^{2}}\left(s-\frac{\Gamma}{\sigma}\right)\left(1-e^{-\sigma(T-t)}\right)\right]
\end{aligned}
$$

Since $a^{*}(t)=\frac{h}{\delta} x$, we have the feedback value of $a$ :

$$
a^{*}(t)=\frac{h}{\delta}\left[\frac{\Gamma}{\sigma}+\left(s-\frac{\Gamma}{\sigma}\right) e^{-\sigma(T-t)}\right]
$$

Moreover, the goodwill is

$$
G^{*}(t)=\frac{e^{-\sigma t} \psi(t)}{2 \delta \sigma^{2}}
$$

where

$$
\psi(t)=h\left[(s \sigma-\Gamma) e^{\sigma(2 t-T)}-(s \sigma-\Gamma) e^{-\sigma T}+2 \Gamma\left(e^{\sigma t}-1\right)\right]+2 \sigma^{2} G_{0} \delta .
$$

Since $\phi<\widehat{\phi}$, we have that $2(1-\phi)(\alpha+c \beta)+c \rho(1-\phi-f \phi)>0$ and so

$$
\begin{aligned}
p_{g}^{*} & >0 \Longleftrightarrow \\
\gamma & =(1-\phi)(\rho+2 \beta)+\rho \phi f[\phi(1+f)-2] \\
& =f^{2} \phi^{2} \rho+f \phi \rho(\phi-2)+(1-\phi)(\rho+2 \beta)>0 .
\end{aligned}
$$

Note that

$$
\gamma \geq f^{2} \phi^{2} \rho+f \phi \rho(\phi-2)+(1-\phi) \rho \equiv \gamma_{1} .
$$

Since $\rho>0$, we have that $\gamma_{1}>0 \Longleftrightarrow$

$$
y^{2}-(2-\phi) y+(1-\phi)>0 .
$$

(13) holds iff $y<1-\phi$ or $y>1$. But $y<1-\phi$ is equivalent to $\phi<\widehat{\phi}$ which is true. Hence we have $\gamma \geq \gamma_{1}>0$. Consequently, both $p_{g}^{*}$ and $p_{c}^{*}$ are positive.

Furthermore, $\phi<\widehat{\phi}$ implies $p_{c}^{*}<p_{g}^{*}$, so that $D_{c}^{*}(t)>0$ for each $t \in[0, T]$. 
It remains to prove that $D_{g}^{*}(t)>0$.

It is :

$$
\left[\alpha-\beta p_{g}^{*}+\rho\left(p_{c}^{*}-p_{g}^{*}\right)\right]>0,
$$

iff

$$
(\beta+\rho) p_{g}^{*}<\alpha+\rho p_{c}^{*}
$$

Substituting $p_{g}^{*}$ and $p_{c}^{*}$ in inequality (14) we obtain that it is satisfied if

$$
c<\frac{2 \alpha(1-\phi)\left[2 \rho f \phi^{2}(1+f)+(1-\phi)(\rho+2 \beta)-3 \rho f \phi\right]}{[\rho \phi(1+f)-2 \beta(1-\phi)-\rho]^{2}}=\widehat{c}
$$

and so if $c<\widehat{c}$ we have that $D_{g}^{*}>0$.

\section{Appendix B}

We present the feedback Stackelberg solution of deterministic two-person differential games, where player 1 acts as a leader and player 2 as a follower.

Definition 1 For the differential games which as the state equation

$$
\dot{x}(t)=f\left(t, x(t), u^{1}(t), u^{2}(t)\right) \quad x(0)=x_{0}
$$

and cost functionals

$$
L^{i}\left(u^{1}, u^{2}\right)=\int_{0}^{T} g^{i}\left(t, x(t), u^{1}(t), u^{2}(t)\right) d t+q^{i}(x(T)) ; i=1,2
$$

where $[0, T]$ denotes the fixed prescribed duration of the game, $x_{0}$ is the initial state known by both players, $x(t) \in R^{n}$ and $u^{i}(t) \in S^{i} \subseteq R^{m_{i}}(i=1,2) \forall t \in[0, T]$.

The pair of policies

$$
\begin{aligned}
\gamma^{1 *}= & \arg \min _{u^{1} \in S^{1}}\left[\frac{\partial V^{1}}{\partial x} f\left(t, x, u^{1}, T^{2}\left(t, x ; u^{1}, \frac{\partial V^{2}}{\partial x}\right)\right)\right. \\
& \left.+g^{2}\left(t, x, u^{1}, T^{2}\left(t, x ; u^{1}, \frac{\partial V^{2}}{\partial x}\right)\right)\right]
\end{aligned}
$$

and

$$
\gamma^{2 *}(t, x)=T^{2}\left(t, x ; \gamma^{1 *}(t, x), \frac{\partial V^{2}}{\partial x}\right)
$$

constitutes a feedback Stackelberg solutions, where $V^{i}(t, x)$ satistying 


$$
\frac{\partial V^{i}(t, x)}{\partial t}=\frac{\partial V^{i}(t, x)}{\partial x} f\left(t, x, \gamma^{1 *}(t, x), \gamma^{2 *}(t, x)\right)+g^{i}\left(t, x, \gamma^{1 *}(t, x), \gamma^{2 *}(t, x)\right)
$$

with the condition $V^{i}(T, x)=q^{i}(x), \quad i=1,2$ is the corresponding cost-to-go function for players 1 and 2 and

$$
T^{2}\left(t, x ; u^{1}, \frac{\partial V^{2}}{\partial x}\right)=\arg \min _{u^{2} \in S^{2}}\left[\frac{\partial V^{2}}{\partial x} f\left(t, x, u^{1} u^{2}\right)+g^{2}\left(t, x, u^{1}, u^{2}\right)\right]
$$

is the instanteous reaction function of player 2 .

Author Contributions Authors whose names appear on the submission have contributed sufficiently to the scientific work and therefore share collective responsibility and accountability for the results.

Funding Open access funding provided by Università di Foggia within the CRUI-CARE Agreement. No funding was received to assist with the preparation of this manuscript.

\section{Declarations}

Conflict of interest All authors certify that they have no affiliations with or involvement in any organization or entity with any financial interest or non-financial interest in the subject matter or materials discussed in this manuscript.

Ethical Approval The research content of this paper does not involve humans and animals or life science, so we think this paper may not need ethical approval.

Informed Consent The research content of this paper does not involve humans participants, animals or life science, so we think this paper may not need informd consent.

Open Access This article is licensed under a Creative Commons Attribution 4.0 International License, which permits use, sharing, adaptation, distribution and reproduction in any medium or format, as long as you give appropriate credit to the original author(s) and the source, provide a link to the Creative Commons licence, and indicate if changes were made. The images or other third party material in this article are included in the article's Creative Commons licence, unless indicated otherwise in a credit line to the material. If material is not included in the article's Creative Commons licence and your intended use is not permitted by statutory regulation or exceeds the permitted use, you will need to obtain permission directly from the copyright holder. To view a copy of this licence, visit http:// creativecommons.org/licenses/by/4.0/.

\section{References}

Ahmadi, R., \& Yang, R. (2000). Parallel imports: Challenges from unauthorized distribution channels. Marketing Science, 19(3), 279-294.

Banerjee, D. S. (2003). Software piracy: A strategic analysis and policy instruments. International Journal of Industrial Organization, 21(1), 97-127.

Başar, T., \& Olsder, G. J. (1999). Dynamic noncooperative game theory. Philadelphia: SIAM.

Biancardi, M., Di Liddo, A., \& Villani, G. (2020). Fines imposed on counterfeiters and pocketed by the genuine firm. A differential game approach. Dynamic Games and Applications, 10, 58-78.

Buratto, A., Grosset, L., \& Zaccour, G. (2016). Strategic pricing and advertising in the presence of a counterfeiter. IMA Journal of Management Mathematics, 27(3), 397-418. 
Chaudhry, P. E. (Ed.). (2017). Handbook of research on counterfeiting and illicit trade. Cheltenham (UK): Edward Elgar Pub.

Choi, E. K. (2004). Mixed markets with counterfeit producers. In E. K. Choi \& J. Harrigan (Eds.), Handbook of international trade (Vol. II, pp. 427-458). Economic and Legal Analyses of Trade Policy and Institutions: Blackwell Publishing Ltd.

Crettez, B., Hayek, N., \& Zaccout, G. (2020). Non-deceptive counterfeiting and consumer welfare: A differential game approach. In J. Renault (Ed.), Ramsey DM. Advances in dynamic games (pp. 253-296). Springer International Publishing.

Di Liddo, A. (2017). Counterfeiting models (Mathematical/Economic). In A. Marciano \& G. Ramello (Eds.), Encyclopedia of law and economics. Springer.

Di Liddo, A. (2018). Does counterfeiting benefit genuine manufacturer? The role of production costs. European Journal of Law and Economics, 45(1), 81-125.

Di Liddo, A. (2019). Competition in the presence of counterfeiters: the case of fines imposed on counterfeiters and pocketed by the genuine firm. International Game Theory Review, 21(4), 1-26.

El Harbi, S., Grolleau, G., \& Bekir, I. (2014). Substituting piracy with a pay-what-you-want option: Does it make sense? European Journal of Law and Economics, 37(2), 277-297.

Eliashberg, J., \& Jeuland, A. P. (1986). The impact of competitive entry in a developing market upon dynamic pricing strategies. Marketing Science, 5, 20-36.

Grossman, G. M., \& Shapiro, C. (1988a). Counterfeit-product trade. American Economic Review, 78, $59-75$

Grossman, G. M., \& Shapiro, C. (1988b). Foreign counterfeiting of status goods. The Quarterly Journal of Economics, 103, 79-100.

Huang, J., Leng, M., \& Parlar, M. (2013). Demand functions in decision modeling: A comprehensive survey and research directions. Decision Sciences, 44(3), 557-609.

Hu, Y., Guan, Y., \& Liu, T. (2011). Lead-time hedging and coordination between manufacturing and sales departments using Nash and Stackelberg games. European Journal of Operational Research, 210(2), 231-240.

IP Working Group. (2018). IP Rights Infringement. Virtual Round Table Series: A jurisdictional guide to IP litigation. IR Global https:/www.irglobal.com/publications/ip-rights-infringement-ajurisdictional-guide-to-ip-litigation/.

Jørgensen, S., \& Di Liddo, A. (2007). Design imitation in the fashion industry. In M. Quincampoix \& L. V. Thomas (Eds.), Jørgensen S. Advances in dynamic game theory (pp. 569-586). Birkhauser.

Jørgensen, S., Sigué, S.-P., \& Zaccour, G. (2001). Stackelberg leadership in a marketing channel. International Game Theory Review, 3(1), 13-26.

Jørgensen, S., \& Zaccour, G. (2004). Differential games in marketing. Kluwer Academic Publishers.

Martin-Herran, G., Taboubi, S., \& Zaccour, G. (2012). Dual role of price and myopia in a marketing channel. European Journal of Operational Research, 219, 284-295.

Nerlove, M., \& Arrow, K. J. (1962). Optimal advertising policy under dynamic conditions. Economica, 29(114), 129-142.

Novak, A. J., Feichtinger, G., \& Leitmann, G. (2010). A differential game related to terrorism: Nash and Stackelberg strategies. Journal of Optimization Theory and Applications., 144, 533-555.

OECD. (2008). The economic impact of counterfeiting and piracy. Paris: OECD Publishing. , 978-92-6404551-4

OECD, E. (2016). Trade in counterfeit and pirated goods: Mapping the economic impact. OECD Publishing.

OECD, E. (2019). Trends in Trade in Counterfeit and Pirated Goods. Office: Illicit Trade, OECD Publishing, Paris/European Union Intellectual Property. https://doi.org/10.1787/g2g9f533-en

Pohjola, M. (1983). Nash and Stackelberg solutions in a differential game model of capitalism. Journal of Economic Dynamics and Control, 6, 173-186.

Seierstad, A., \& Sydsæter, K. (2002). Optimal control theory with economic applications. Elsevier Science B.V.

Tsai, M. F., Chiou, J. R., \& Lin, C. H. A. (2012). A model of counterfeiting: A duopoly approach. Japan and the World Economy, 24(4), 283-291.

Yao, J. T. (2005a). Counterfeiting and an optimal monitoring policy. European Journal of Law and Economics, 19(1), 95-114.

Yao, J. T. (2005b). How a luxury monopolist might benefit from a stringent counterfeit monitoring regime. International Journal of Business and Economics, 4(3), 177-192. 
Zhang, J., Hong, L. J., \& Zhang, R. Q. (2012). Fighting strategies in a market with counterfeits. Annals of Operations Research, 192(1), 49-66.

Publisher's Note Springer Nature remains neutral with regard to jurisdictional claims in published maps and institutional affiliations. 